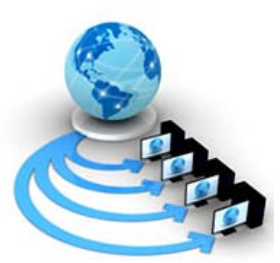

\title{
REVIEW ON SATELLITE IMAGE CLASSIFICATION BY MACHINE LEARNING AND OPTIMIZATION APPROACHES
}

\author{
Shelly Rani \\ Student of Master in Technology \\ Department of Computer Science and Application \\ Chaudhary Devi Lal University, Sirsa, Haryana, India
}

\author{
Sakshi Dhingra \\ Assistant Professor \\ Department of Computer Science and Application \\ Chaudhary Devi Lal University, Sirsa, Haryana, India
}

\begin{abstract}
Image classification is an unpredictable procedure that might be influenced by many variables. This paper orders different satellite pictures with its highlights and distinctive sorts of the supervised learning algorithm. This writing audit proposes that outlining an appropriate remote image-processing method is an essential for an effective grouping of remotely detected information into a topical guide. Viable utilization of various highlights of remotely detected information and the determination of a reasonable arrangement technique is particularly noteworthy for enhancing characterization exactness.
\end{abstract}

Keywords - Satellite images, optimization, features, accuracy

\section{INTRODUCTION}

In providing geographical information satellite images play a vital role. The quantitative and qualitative information is provided by the satellite and remote sensing images to reduce the complexity of study time and field work. At regular intervals, the satellite remote sensing technologies collect images/data. At the data centers, the volume of information gathered is substantial and it is developing exponentially as the innovation is developing at a quick speed. From the huge satellite pictures, there is a solid requirement for a productive and compelling component to translate and extricate important data. To isolate information from an enormous number of satellite pictures, the satellite picture gathering is a viable strategy. Satellite picture portrayal is a system of accumulation pixels into critical classes. This technique is known as the multi-step work process. From various remotely identified pictures, the satellite picture gathering can be in a manner of isolating information. This request is not troublesome, but instead, in the satellite picture portrayal process, the agent needs to take various decisions and choices. In an interpretation of spatial data mining, remote distinguishing pictures and focus diverse vegetation sorts, for instance, agribusiness and foresters et cetera the satellite picture gathering is incorporated [1].

Dominant part of information that is shared and gotten to over the web are as media substances. The multimedia system information equivalent to pictures and videos are greater approachable owing to visual contents.[13]

\subsection{Applications of Satellite Image Classification:}

There are many applications of satellite image classification, i.e. Field surveys, Meteorology, Oceanography, Fishing, Agriculture, Biodiversity conservation, Forestry, Intelligence, For an application extract information, Disaster management, Spatial data mining, Thematic map creation, Digital and visual satellite image interpretation [1].
In the second section we studied the literature review of the previous papers and further discussed the literature review table. In the third section conclusion is discussed.

\section{LITERATURE REVIEW}

Wen Yang et. al. [2] This paper shows a novel framework keeping an eye out for the arrangement time of satellite pictures when constrained stamped information is accessible together with a lot of unlabeled information. Rather than utilizing semisupervised classifiers, it dealt with the issue by taking in a sporadic state highlight, called semi-supervised outfit projection (SSEP). More reliably, we propose to address a photo by anticipating it onto a troupe of weak planning (WT) sets endeavored from a Gaussian figure of various part spaces. Given a course of action of pictures with compelled named ones, in a split second isolate preliminary parts, for instance shading and surfaces, to shape a low-level picture depiction. At that point propose another semi-directed testing check to hide away a social event of educational WT sets by abusing these part spaces with a Gaussian customary proclivity, which ensures both the immovable quality and contrasting properties of multi-classifier..

J. Senthilnath et.al. [3] This paper asked about another Glowworm Swarm Optimization (GSO) gathering mean dynamic part and centering of adjusted multi-spooky satellite picture course of action (arrive cover mapping issue). Among the diverse inclinations and organizations of remote perceiving, a champion among the most basic has been to apply in dealing with the issue of land cover mapping. Picture gathering shapes the purpose of meeting of the response for the land cover mapping issue. No single classifier can show to design all the genuine land cover classes of a urban locale in a connecting with way. In unsupervised depiction structures, the changed time of social affairs to arrange a colossal database isn't abused to their most remarkable most remote point. The proposed thinking examines for the best number of clusters and its inside using Glowworm Swarm Optimization (GSO). Using these 
packs, depict by solidifying in setting of parametric framework (k-induces system).

Jamshid Tamouk et.al. [4] This paper endeavours to locate the most precise grouping technique among parallelepiped, least separation and chain strategies. Besides, this review additionally difficulties to locate the appropriate blend of groups, which can prompt better outcomes on the off chance that mixes of groups happen. Subsequent to contrasting these three strategies, the chain strategy over play out alternate techniques with $79 \%$ general precision. Henceforth, it is more exact than least separation with $67 \%$ and parallelepiped with $65 \%$. Then again, in light of groups elements, and furthermore by joining a few analysts discoveries, a table was made which incorporates the principle protests on the land and the appropriate blend of the groups for precisely identifying of land cover articles. Amid this procedure, it was watched that band 4 (out of 7 groups of Landsat 5TM) is the band, which can be utilized for expanding the exactness of the joined groups in recognizing objects on the land.

S.Manthira Moorthi et.al. [5] The aim of the survey is to utilize SVM framework for gathering multi shocking satellite picture dataset and separate the general precision and the standard picture arrangement method. LISS-3 and AWIFS sensors information from Resourcesat-1, Indian Remote Sensing (IRS) organize were utilized for this examination. Here, a segment of the open source gadgets was utilized to check whether SVM can be a potential grouping framework for common satellite picture arrangement.

X. Gigandet et.al. [6] In this paper proposed a figuring for high-assurance satellite picture order that merges nonsupervised division with a supervised grouping. Both multispooky data and adjacent spatial priors are used as a piece of the Gaussian Hidden Markov Random Field (GHMRF) appear for the division. By then, two classifiers, Mahalanobis separate classifier, and SVM are inspected using force, surface and shape features. The endorsement is done subjectively and quantitatively by a relationship with a manual grouping used as a ground truth.

Biplab Banerjee et.al.[7] This paper addresses the issue of unsupervised land-cover grouping of remotely detected multispectral satellite images from the point of view of bunch outfits and self-learning. The group troupes join multiple information segments produced by various clustering algorithms into a single strong arrangement. A group gathering based technique is proposed here for the introduction of the unsupervised iterative expectation maximization (EM) algorithm which in the end creates a superior estimate of the bunch parameters considering a specific measurable model is taken after to fit the information. The technique expects that the quantity of landcover classes is known. A novel strategy for creating a reliable naming plan for each clustering of the agreement is presented for group outfits. A maximum likelihood (ML) classifier is consequently prepared on the refreshed parameter set acquired from the EM step and is additionally used to group whatever is left of the picture pixels. The self-learning classifier, however, prepared with no outer supervision, lessens the impact of information covering from various groups which generally a single clustering algorithm neglects to recognize.

Graeme G et.al. [8] A review has been completed of 15 years of distributed associate investigated probes satellite image classification. The point of the review was to survey the level of advance being made in thematic mapping through improvements in classification calculations and furthermore in frameworks methodologies, for example, post classification examination, multi classifier integration, and information combination. The consequences of more than 500 revealed classification analyses were quantitatively dissected. This included examination of connections between classification exactness and date of production, and in addition amongst precision and different trial parameters, for example, number of classes, size of highlight vector, determination of satellite information, and test territory. Examinations were additionally made between various sorts of procedure, for example, neural system and non-neural methodologies.

Kan Xu et.al. [9] This paper showed a profitable unsupervised semantic characterization strategy for high-assurance satellite pictures. It incorporates stamp cost, which can rebuff an answer in light of a plan of names that appear in it by streamlining of essentialness, to the self-assertive fields of sit without moving subjects, and an iterative algorithm is thusly proposed to influence a number of classes finally to be centered to a reasonable level. Differentiated and other said grouping algorithms, its procedure not only can get exact semantic division comes to fruition by greater scale structures also can normally select a number of bits. The test comes to fruition in a couple of scenes have displayed its practicality and generosity.

Navdeep Kaur Johal et.al. [10] This paper oversees picture arrangement by using swarm registering framework. In this work, it used another swarm data bundling procedure in view of blossom fertilization by fake honey bees to aggregate the satellite picture pixels. The purpose of batching is to separate a game plan of data centers into self-near social events. Those bundles will be furthermore portrayed using Biogeography Based Optimization. The results demonstrate that significantly exact order of the satellite picture is gained by using the proposed count.

Susan Kathleen Langley et.al. [11] In this paper single date Landsat TM information gave a solid methodology to mapping vegetation cover in this semi-dried area. Single picture gathered in September may be more right than the others because of more unmistakable successful responses for the target COMPARISON OF SINGLE DATE AND MULTITEMPORAL SATELLITE IMAGE 409 vegetation classes and less shadows in this geographic region starting at now of year. Solid maps can subsequently be passed on quickly and monetarily in case they picked picture is obtained at the time of most over the top phenological arrangement.

Aykut AKGÜN et.al. [12] In this particular circumstance, strategies for upgrading the request of land use with satellite remote identifying data consolidate the use of fitting automated data. With a particular ultimate objective to fulfill this task, assurance of the most suitable satellite picture, band blend, and the classifier are basic. In addition, the photo dealing with is key and assorted periods of it, for instance, isolating of gatherings and fundamental section examination should be associated before evaluation. Each one of these concentrations was associated with this examination and it has been seen that most prominent likelihood classifier was the most suitable game plan system for arriving use mapping reason. Slightest divisions classifier was moreover chosen as sensible as the most extraordinary likelihood classifier. 
Table 1: A brief overview of this literature review

\begin{tabular}{|c|c|c|c|c|c|c|}
\hline $\begin{array}{l}\text { Author's } \\
\text { Name }\end{array}$ & Year & Features & Classification Type & $\begin{array}{l}\text { Performance } \\
\text { Parameters }\end{array}$ & $\begin{array}{l}\text { Dataset/ } \\
\text { Database }\end{array}$ & $\begin{array}{l}\text { Result } \\
\text { (An average } \\
\text { value) }\end{array}$ \\
\hline $\begin{array}{l}\text { Biplab } \\
\text { Banerjee } \\
\text { et.al. }\end{array}$ & 2015 & $\begin{array}{l}\text { Self-training } \\
\text { based } \\
\text { Unsupervised } \\
\text { satellite image } \\
\text { classification }\end{array}$ & & $\begin{array}{l}\text { Overall } \\
\text { accuracy }\end{array}$ & $\begin{array}{l}\text { 1)Medium } \\
\text { Resolution } \\
\text { Sardinia } \\
\text { Dataset } \\
\text { 2)High } \\
\text { Resolution } \\
\text { Quickbird } \\
\text { dataset }\end{array}$ & $\begin{array}{l}\text { Sardinia } \\
\text { Dataset- } \\
86.45+20.29 \\
\\
\text { Quickbird } \\
\text { Dataset- } \\
91.41+0.00\end{array}$ \\
\hline $\begin{array}{l}\text { Wen Yang } \\
\text { et. al. }\end{array}$ & 2015 & $\begin{array}{l}\text { Structural \& } \\
\text { Textural } \\
\text { Features }\end{array}$ & $\begin{array}{l}\text { Semisupervised } \\
\text { Classification }\end{array}$ & Accuracy & $\begin{array}{l}19 \text { number } \\
\text { of-class } \\
\text { satellite } \\
\text { scene } \\
\text { dataset } \\
21 \text { number } \\
\text { of-class } \\
\text { satellite } \\
\text { scene } \\
\text { dataset }\end{array}$ & $\begin{array}{l}\text { The most } \\
\text { noteworthy } \\
\text { Accuracy is } \\
73.82 \% \text { for 19- } \\
\text { Class, 65.34\% } \\
\text { for 21-Class, } \\
\text { most elevated } \\
\text { Accuracy is } \\
73.75 p e r-c e n t ~ \\
\text { with supervised } \\
\text { classifiers ,for } \\
19 \text { number of- } \\
\text { Class and } 66.49 \\
\text { per-cent for } 21 \\
\text { number of-Class } \\
\text { with semi- } \\
\text { supervised } \\
\text { classifiers. }\end{array}$ \\
\hline $\begin{array}{l}\text { Jamshid } \\
\text { Tamouk } \\
\text { et.al. }\end{array}$ & 2013 & $\begin{array}{l}\text { Based on } \\
\text { Band Features }\end{array}$ & $\begin{array}{l}\text { Supervised } \\
\text { Classification Method } \\
\text { (Parallelepiped } \\
\text { minimum distance } \\
\text { chain method) }\end{array}$ & $\begin{array}{l}\text { User } \\
\text { Accuracy,Pro } \\
\text { ducer } \\
\text { Accuracy, } \\
\text { Overall } \\
\text { Accuracy }\end{array}$ & $\begin{array}{l}\text { LANDSAT } \\
\text { 5TM } \\
\text { DATASET }\end{array}$ & $\begin{array}{l}79 \text { per-cent } \\
\text { accuracy, } \\
\text { minimum } \\
\text { distance (with } \\
67 \quad \text { per-cent } \\
\text { accuracy), }\end{array}$ \\
\hline $\begin{array}{l}\text { J. } \\
\text { Senthilnath } \\
\text { et.al. }\end{array}$ & 2011 & $\begin{array}{l}\text { Color } \\
\text { Composite }\end{array}$ & $\begin{array}{l}\text { Unsupervised } \\
\text { Classification(Multi- } \\
\text { Spectral satellite image } \\
\text { classification) }\end{array}$ & $\begin{array}{l}\text { Overall } \\
\text { efficiency }\end{array}$ & $\begin{array}{l}\text { LandSat } \\
\text { Dataset }\end{array}$ & $\begin{array}{l}\text { Nearly } 18 \text { per- } \\
\text { cent increase } \\
\text { i.e.Average } \\
\text { efficiency has } \\
\text { improved from } \\
\text { 69.0per-cent to }\end{array}$ \\
\hline
\end{tabular}




\begin{tabular}{|c|c|c|c|c|c|c|}
\hline & & & & & & 81.4per-cent \\
\hline $\begin{array}{l}\text { S.Manthira } \\
\text { Moorthi } \\
\text { et.al. }\end{array}$ & 2011 & Color Feature & $\begin{array}{l}\text { Supervised } \\
\text { Classification Method } \\
\text { (SVM classification \& } \\
\text { Kernel based learning } \\
\text { approach) }\end{array}$ & $\begin{array}{l}\text { Overall } \\
\text { Accuracy, } \\
\text { Kappa } \\
\text { coefficient }\end{array}$ & $\begin{array}{l}\text { Training } \\
\text { sample } \\
\text { dataset }\end{array}$ & $\begin{array}{l}\text { Overall } \\
\text { accuracy 92per- } \\
\text { cent for both } \\
\text { SVM kernel } \\
\text { types as } \\
\text { compared to the } \\
\text { maximum } \\
\text { likelihood } \\
\text { classification }\end{array}$ \\
\hline $\begin{array}{l}\text { X. } \\
\text { Gigandet } \\
\text { et.al. }\end{array}$ & 2005 & $\begin{array}{l}\text { Texture \& } \\
\text { Shape } \\
\text { Features }\end{array}$ & $\begin{array}{l}\text { Supervised } \\
\text { Classification (Region- } \\
\text { based satellite image } \\
\text { classification) }\end{array}$ & $\begin{array}{l}\text { Overall } \\
\text { accuracy }\end{array}$ & $\begin{array}{l}\text { Quickbird } \\
\text { Satellite }\end{array}$ & $\begin{array}{l}\text { Pixel based- } \\
77.9 \% \\
\text { Region based- } \\
84.3 \%\end{array}$ \\
\hline
\end{tabular}

\section{CONCLUSION}

The Success of an image classification relies upon many elements. These components incorporate the accessibility of high-quality remotely detected symbolism, assistant data, the blueprint of a legitimate order technique, the analyst's aptitudes and experiences are the most imperative ones. For a specific report, it is frequently hard to recognize the best classifier because of the absence of a rule for determination and the accessibility of reasonable arrangement algorithms to be dealt with. Similar investigations of various classifiers are in this manner often happened. Also, the mix of various arrangement approaches has appeared to be useful for the development of order precision. In this paper, a survey of the present progress was displayed. We exhaustively characterized the procedures into three gatherings, in particular, format organizing based methodologies, data based systems, and machine learningbased strategies, and completely investigated them exclusively.

\section{REFERENCES}

[1] Sunitha Abburu and Suresh Babu Golla. "Satellite image classification methods and techniques: A review." International journal of computer applications, vol. 119, no. 8, pp. 0975-8887, June 2015.

[2] Wen Yang, Xiaoshuang Yin, and Gui-Song Xia. "Learning highlevel features for satellite image classification with limited labeled samples." IEEE Transactions on Geoscience and Remote Sensing, vol.53, no.8, pp. 4472-4482, Aug 2015.

[3] J.Senthilnath,S.N.Onkar,V.Mani,Tejovanth N,P.G. Diwakar,Archana Shenoy B. "Multi-spectral satellite image classification using glowworm swarm optimization." Geoscience and Remote Sensing Symposium (IGARSS), IEEE International, Oct. 2011.

[4] Jamshid Tamouk, Nasser Lotfi, and Mina Farmanbar. "Satellite image classification methods and Landsat 5TM Bands." International Journal of Computer Science and Information Security, vol.11, no.6, pp. 99-103, June 2013.
[5] S. Manthira Moorthi, Indranil Misra,Rajdeep Kaur,Nikunj P Darji and R. Ramakrishnan. "Kernel based learning approach for satellite image classification using support vector machine." Recent Advances in Intelligent Computational Systems (RAICS), IEEE, Nov.2011.

[6] X.Gigandet, M.Bach Cuadra, A.pointet, L.Cammoun, R.Caloz and J.-Ph.Thiran. "Region-based satellite image classification: method and validation." Image Processing, 2005, ICIP 2005, IEEE International Conference, vol. 3, March 2006.

[7] Biplab Banerjee,Francesca Bovolo,Avik Bhattacharya,Lorenzo Bruzzone, Subhasis Chaudhuri and B Krishna Mohan." A new self-training-based unsupervised satellite image classification technique using cluster ensemble strategy." IEEE Geoscience and Remote Sensing Letters, vol. 12, no. 4, pp. 741-745, 2015.

[8] Graeme G. Wilkinson. "Results and implications of a study of fifteen years of satellite image classification experiments." IEEE Transactions on Geoscience and remote sensing, vol.43, no.3, pp. 433-440, March 2015.

[9] Kan Xu, Wen Yang, Gang Liu and Hong Sun. "Unsupervised satellite image classification using Markov field topic model." IEEE Geoscience and Remote Sensing Letters, vol. 10, no.1, pp. 130-134, Jan 2013.

[10] Navdeep Kaur Johal, Samandeep Singh and Harish Kundra. "A hybrid FPAB/BBO algorithm for satellite image classification." International Journal of Computer Applications, vol.6, no.5, pp.0975-8887, sept. 2010.

[11] Susan Kathleen Langley, Heather M. Cheshire and Karen S. Humes. "A comparison of single date and multitemporal satellite image classifications in a semi-arid grassland." Journal of Arid Environments, vol. 49, no.2, pp. 401-411, 2001.

[12] Aykut Akgün, A. Hüsnü Eronat, and Necdet Türk. "Comparing Different Satellite Image Classification Methods: An Application In Ayvalik District, Western Turkey." The 4th International Congress for Photogrammetry and Remote Sensing, Istanbul, Turkey, 2004.

[13] Manpreet Kaur, Sakshi Dhingra "Retrieval of images on the Basis of Contents: a Review.” International Journal of Engineering Development and Research, vol. 4, no.2, pp. 17341740, 2016 